\title{
Drug effects and avoidance-extinction in rats: A test of the drug novelty hypothesis using ethanol*
}

\author{
ZALMAN AMIT $\div$ and D. ZISKIND \\ Tel-Aviv University', Tel-Avil, Israel \\ and \\ MORRIE BAUM \\ University of Moncton, Moncton, New Brunswick, Canada
}

\begin{abstract}
The "drug novelty hypothesis" was tested directly by giving rats experience with intraperitoneal injections of ethanol on days prior to avoidance training. This preavoidance experience with ethanol was found to eliminate the prolonged extinction of avoidance responding observed after a single exposure to ethanol. It is suggested that these findings confirm the novelty hypothesis in an active avoidance situation. Possible mechanisms of the drug novelty effect were discussed.
\end{abstract}

Baum (1969) found that alcohol increased the resistance to extinction of an active avoidance response in rats, and later replicated the effect in mice (Baum, 1971). He called this effect "paradoxical" because the results were opposite to those anticipated on the assumption that alcohol reduces fear and fear-motivated behavior. A similar increase in resistance to extinction of avoidance behavior in rats was found after injection of hashish resin (Jaffe \& Baum, 1971). In a "comment" on the similar action of these two unrelated drugs, Amit and Baum (1970) suggested that the experience of being in a drug state for a pharmacologically naive $S$ is aversive and acts to increase fear in the avoidance situation, thus resulting in increased resistance to extinction.

This study was designed to test the novel drug-state hypothesis of Amit and Baum (1970) directly. If the "novelty" hypothesis is correct, one should expect a difference in the resistance to extinction of avoidance following drug administration, depending on whether or not the animals are naive with respect to the drug or whether they have experienced the drug state before. The present experiment employed a 2 by 2 factorial design, with four groups of rats receiving ethanol or saline (one factor) prior to avoidance extinction, after a previous history of exposure or no exposure (second factor) to being in the drugged state.

\section{METHOD}

Subjects

The Ss were 48 male rats of the "Cancer Research Strain," obtained from the Weizman Institute, Rechovot, Israel. At the beginning of the experiment, they were 90 days old and weighed

\footnotetext{
*This research was supported in part by a grant from the Licensed Beverage Industries, Inc., to Z. Amit.

$\div$ Now at the Department of Psychology. Sir George Williams Iniversity, Montreal. Qucbec. Canada.
}

approximately $320 \mathrm{~g}$. All animals were housed in plastic group cages, three to five rats per cage, with water and Purina Rat Chow available ad lib.

\section{Apparatus}

A one-way avoidance apparatus was employed. It consisted of a modified two-chamber shuttlebox divided in half by a translucent Plexiglas divider with a rectangular opening. Each chamber measured $7 \times 8 \times 10$ in. high, and the floor consisted of a seesaw grid. Shock of $0.6 \mathrm{~mA}$ could be delivered to the grid of the left chamber via a Grason-Stadler shock generator and scrambler. The left (shock) chamber had large white cards taped to three walls, while the right chamber had three gray walls. The front wall of both chambers were of transparent Plexiglas.

\section{Procedure}

The Ss were assigned randomly to one of four groups: experienced saline (ES. $N=10$ ), experienced ethanol ( $E E$, $N=10$ ), naive ethanol ( $N E, N=10$ ), and naive saline ( $N S$, $N=18$ ). The $E E$ and $E S$ groups received daily injections of $7.5 \mathrm{cc}$ of $20 \%$ ethanol in water per kilogram of body weight or $7.5 \mathrm{cc}$ of saline per kilogram of body weight, respectively, for 14 days. All injections were intraperitoneal. The naive groups which were not otherwise treated were handled.

The rats were run individually on an avoidance learning task to a criterion of 10 consecutive avoidances, with an intertrial interval of $30 \mathrm{sec}$. A period of $10 \mathrm{sec}$ elapsed between placement in the shock chamber and shock presentation. Following the intertrial interval after avoidance or escape, the rat was removed from the "safe" chamber and placed into the shock chamber by hand. Upon performance of 10 consecutive shock avoidances. the rat was injected (ethanol or saline) and placed into a plastic cage for $10 \mathrm{~min}$. The number of trials to extinction was then determined by replacing the rat in the one-way shuttlebox with the shock turned off. Criterion for extinction was 2.5 consecutive minutes spent in the shock chamber, and extinction trials were similar to acquisition trials except that the shocker was disconnected. Both in the acquisition and extinction sessions, the rats were initially placed in the "safe" chamber for an intertrial interval.

\section{RESULTS}

Because avoidance-extinction data are typically not 


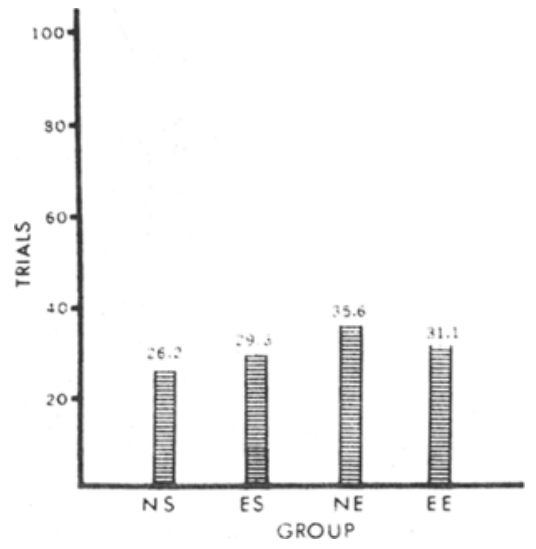

Fig. 1. Mean number of trials to acquisition of shock avoidance behavior for the four groups tested (NS = naive saline; $\mathrm{ES}=$ experienced saline: $\mathrm{NE}=$ naive ethanol; $\mathrm{EE}=$ experienced ethanol).

normally distributed, nonparametric statistics were used throughout the data analysis. The results are shown in Figs. 1 and 2. The acquisition of the avoidance response was similar in all four groups, and showed no effect based on drug or placebo pretreatments (Kruskal-Wallis, $\mathrm{H}=0.89$ ). The mean number of trials to extinction required by all four groups is shown in Fig. 2, and a Kruskal-Wallis one-way analysis of variance showed the groups significantly different in this measure $(\mathrm{H}=10.17$, $\mathrm{p}<.02)$. The $\mathrm{NE}$ group required the greatest number of trials to extinction. A Mann-Whitney $U$ test showed that the difference in number of trials of the naive compared to the experienced ethanol group was significant $(p<.05)$. The number of trials to extinction of the NE group was also higher than that of the NS group $(p<.05)$. The difference in number of trials to extinction between the EE and the ES groups was not significant. The number of trials to extinction of the NS group was not significantly greater than that of the ES group.

The number of responses made in extinction by the various groups was quite variable. The means, ranges, and standard deviations, respectively, of the four groups were as follows: Group NS-35.1, 11.53, and 14.62; Group ES-9.9, 6-21, and 4.80; Group NE-92.7, 54-147, and 32.58; and Group EE-32.0, 19-56, and 13.41 .

\section{DISCUSSION}

On the basis of the results obtained with ethanol (Baum, 1969, 1971) and hashish (Jaffe \& Baum, 1971), Amit and Baum (1970) postulated that the state of being drugged, rather than the drug itself, could modulate extinction behavior for a naive S. Cappell, LeBlanc, and Endrenyi (in press) attempted to test this notion by comparing the effects of chlordiazepoxide and ethanol on extinction of a conditioned taste aversion. They found that the notion that the aversiveness of the novel drug state compounded by the aversiveness of the CS would extend extinction behavior did not predict the more rapid extinction produced by chlordiazepoxide in their study. An alternative test of the novel drug-state hypothesis would be to compare avoidance behavior of naive vs experienced Ss on one drug. The results of the present study support the assumption that the aversive novelty of the drug state is the modulator of the extinction phenomenon.

The results of these various studies suggest that there can be two effects of a drug administered to a pharmacologically naive animal. First, there is an effect of the novelty of the drug state that may serve to increase fear and strengthen avoidance responding. Secondly, there is the pharmacologic effect of the drug on the behavior. These two effects can interact in different ways. In the case of alcohol's being administered for the first time prior to avoidance extinction, the novelty effect seems to predominate. In the case of chlordiazepoxide, the pharmacological action appears to be stronger than any novelty effect, at least in the case of the extinction of a conditioned taste aversion (Cappell et al, in press).

The mechanism of the drug novelty effect and the kinds of drugs that may produce it remain subjects of further investigation. The novelty effect may be due to an enhanced state of fear due to the novelty of being in a new drug state, as suggested earlier. On the other hand, Thiessen ${ }^{1}$ has suggested that the effect of alcohol in prolonging avoidance responding in extinction is due to the stress of the alcohol injection which releases ACTH, which has been shown to prolong avoidance-extinction responding (Bohus \& DeWied, 1966). It may be that this ACTH-releasing stress reaction to alcohol injection is what habituates out with repeated injections, and this would provide an alternative mechanism for the effect obtained in this study. Clearly there is more than one

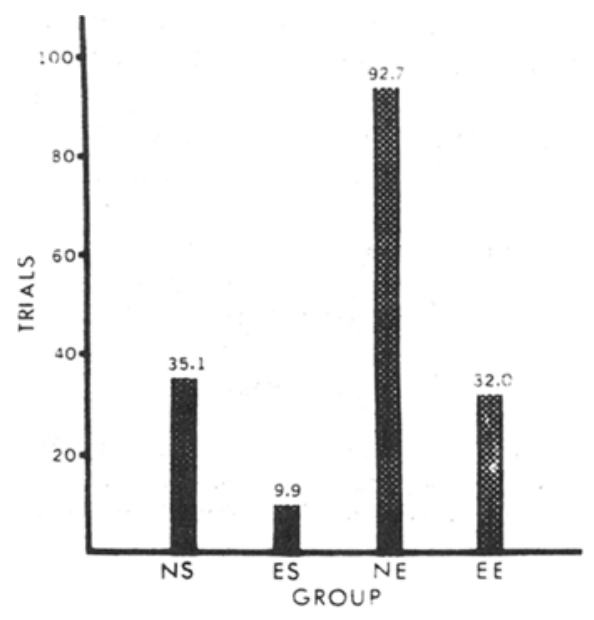

Fig. 2. Mean number of trials to extinction of shock avoidance behavior for the four groups tested (NS = naive saline; ES = experienced saline: $\mathrm{NE}=$ naive ethanol; $\mathrm{EE}=$ experienced ethanol). 
possible explanation for the drug novelty effect and further research is warranted.

\section{REFERENCES}

Amit, Z., \& Baum, M. Comment on the increased resistance-to-extinction of an avoidance response induced by certain drugs. Psychological Reports, 1970, 27. 310.

Baum, M. Paradoxical effect of alcohol on the resistance to extinction of an avoidance response in rats. Journal of Comparative \& Physiological Psychology, 1969. 69. 238-240.

Baum, M. Effect of alcohol on the resistance-to-extinction of an avoidance response: Replication in mice. Physiology \& Behavior, 1971, 6, 307-309.
Bohus, B., \& DeWied, D. Inhibitory and facilitatory effect of two related peptides on extinction of avoidance behavior. Science, 1966, i53, 318-320.

Cappell, H. D., LeBlanc, A. E., \& Endrenyi. L. Effects of chlordiazepoxide and ethanol on the extinction of a conditioned taste aversion. Physiology \& Behavior, in press.

Jaffe, P. G., \& Baum, M. Increased resistance-to-extinction of an avoidance response in rats following the administration of hashish resin. Psychopharmacologia, 1971, 20, 97-102.

\section{NOTE}

1. D. D. Thiessen. personal communication to M. Baum.

(Received for publication July 17, 1972: resubmission received August 30, 1972.) 